\title{
HUBUNGAN JARAK PEMASANGAN TERAPI INTRAVENA DARI PERSENDIAN TERHADAP WAKTU TERJADINYA FLEBITIS*
}

\author{
Dewi Gayatri, Hanny Handiyani**
}

\begin{abstract}
Abstrak
Penelitian ini bertujuan untuk mengidentifikasi hubungan jarak pemasangan terapi intravena dari persendian dengan waktu terjadinya flebitis. Desain penelitian yang digunakan adalah penelitian kohort prospektif dengan lama pengamatan 72 jam. Sampel yang diambil berjumlah 120 responden. Teknik analisis yang digunakan dalam penelitian ini adalah survival analysis. Penelitian ini menyimpulkan bahwa semakin jauh jarak pemasangan terapi intravena dari persendian maka risiko untuk terjadi flebitis akan semakin meningkat. Hal ini dapat disebabkan karena kurangnya fiksasi dan dekatnya persambungan selang kanul dengan persendian lainnya. Faktor lain yang akan meningkatkan risiko terjadinya flebitis adalah cairan dengan osmolalitas tinggi dan pemakaian balutan konvensional. Hal utama yang direkomendasikan dari penelitian ini adalah pemasangan terapi intravena sebaiknya berjarak minimal 3-7 cm dari persendian serta diperlukan penelitian lanjutan di mana jumlah sampel dan desain yang lebih baik diterapkan.
\end{abstract}

Kata kunci: balutan, cairan, jarak pemasangan, terapi intravena

\begin{abstract}
This research aimed to identify the relationship between the distance vein puncture site from joint and survival rate of phlebitis. This research used cohort design with 72 hour observation. The size sample of this research was 120 respondents. Analysis methods which using in this research was survival analysis. The conclusions of this research are the distance vein puncture which far joint can increase phlebitis probability, osmolality and types of dressing can increase phlebitis probability too. The recommendations of this research are the inserting of infusion therapy is minimum 3-7 cm from joint and use the modern dressing. Besides that, the research have been recommending the next research which is using better design and bigger samples size.
\end{abstract}

Key words: dressing, intravenous therapy, liquid, vein puncture

\section{LATAR BELAKANG}

Terapi intravena atau yang biasa disebut dengan terapi infus merupakan metode yang efektif untuk mensuplai cairan, elektrolit, nutrisi, obat melalui pembuluh darah (intravaskular). Terapi intravena diinstruksikan oleh dokter tetapi perawatlah yang bertanggung jawab pada pemberian dan mempertahankan terapi tersebut pada pasien (Perry \& Potter, 2001). Craven dan Hirnle, (2006) juga menyatakan hal yang serupa, yaitu perawat bertanggung jawab untuk memasang, memonitor, serta mengajarkan pada klien hal yang berkaitan dengan terapi infus.

Lebih dari $80 \%$ pasien rawat akut mendapatkan terapi intravena sebagai bagian rutin dariperawatan di rumah sakit (Stevens \& Anderson, 2003). Adanya terapi ini sering menyebabkan terjadinya komplikasi antara lain terjadi flebitis. Flebitis adalah peradangan pada vena (Booker \& Ignatavicius, 1996). Biasanya disebabkan karena teknik pemasangan, kondisi pasien, kondisi vena, jenis dan $\mathrm{pH}$ obat dan cairan, filtrasi, serta ukuran, panjang serta materi (bahan) selang infus .

Campbell, 1998 (dalam Pujasari dan Sumarwati, 2002) menyatakan bahwa kejadian flebitis di rumah sakit berkisar antara 20-80\%. Untuk di Indonesia belum ada angka yang pasti tentang prevalensi flebitis mungkin disebabkan penelitian yang berkaitan dengan terapi intravena dan publikasinya masih jarang namun Pujasari dan Sumarwati (2002) menyatakan bahwa flebitis di salah satu rumah sakit Jakarta didapatkan 10\%. Angka 
tersebut memang tidak terlalu besar namun masih di atas standar yang ditetapkan oleh Intravenous Nurses Society (INS) yaitu 5\%.

Flebitis secara umum terbagi 3 jenis berdasarkan penyebabnya, yaitu flebitis supuratif, flebitis kimiawi, dan flebitis mekanik. Angeles (1997) menyatakan bahwa flebitis mekanik disebabkan karena kanul yang terlalu besar untuk pembuluh vena dan pemasangan kanul dekat persendian. Pemasangan kanul dekat persendian oleh Angeles, 1997 dinyatakan dapat menyebabkan flebitis ketika pasien bergerak dapat memicu pergerakan kanul sehingga melukai dinding pembuluh darah.

\section{Perumusan Masalah}

Pemasangan terapi intra vena seringkali menimbulkan komplikasi, salah satu komplikasi yang sering terjadi adalah flebitis. Angka kejadian flebitis di Indonesia masih di atas dari standar yang ditetapkan oleh INS. Salah satu faktor yang mempengaruhi kejadian flebitis adalah jarak pemasangan yang terlalu dekat dengan persendian namun kejelasan seberapa erat hubungan jarak pemasangan terapi intravena dari persendian dengan waktu terjadinya flebitis sejauh ini tim peneliti belum menemukannya selain itu hasil penelitian yang berkaitan dengan kejadian flebitis di Indonesia sangat kurang. Berdasarkan hal-hal tersebut, penelitian ini dilakukan bertujuan untuk menjawab pertanyaan "bagaimanakah hubungan jarak pemasangan terapi intravena dari persendian dengan waktu terjadinya flebitis setelah dikontrol oleh faktor pengganggu?"

\section{Metode Penelitian}

Penelitian ini meggunakan desain kohort prospektif karena pada penelitian ini hanya mengamati dan mencatat paparan dan kejadian yang diamati dan tidak dengan sengaja mengalokasikan paparan (Murti, 1997). Pada penelitian ini, pengontrolan yang dilakukan hanya untuk mencegah terjadinya flebitis supuratif yang diakibatkan dari pemasangan yang tidak aseptic antiseptic sedangkan pengontolan terhadap faktorfaktor potensial pengganggu yang lain akan dilakukan melalui uji statistik.

\section{HASIL}

\section{Analisis Univariat}

Penelitian ini dilakukan di 3 rumah sakit di Jakarta. Adapun jumlah total sampel yang diperoleh selama pengumpulan data adalah 120 responden, sebenarnya data yang diperoleh adalah 160 responden namun karena pengisian yang tidak lengkap dari kolektor data maka data tersebut tidak diolah dalam penelitian ini.

Penelitian ini mendapatkan hasil bahwa terdapat $35,8 \%$ (43 responden) yang mengalami flebitis. Jenis kelamin rata-rata 57,5\% laki-laki (69 responden). Umur rata-rata dalam penelitian ini 38,9 tahun dengan standar deviasi 17,8 tahun.

Jarak rata-rata pemasangan intravena dari persendian adalah 8,8 $\mathrm{cm}$ dengan standar deviasi 5,9 $\mathrm{cm}$. Hanya $6,7 \%$ (8 responden) yang mendapatkan terapi guyur. Umumnya mendapatkan terapi cairan dengan $\mathrm{pH}$ normal 73,3\% (88 responden) dan hanya $6,7 \%$ ( 8 responden) yang mendapatkan terapi cairan dengan osmolalitas tinggi.

Tempat pemasangan terapi intravena adalah pada vena Basilika (45,8\%) dan daerah dorsal (30\%). Tingkat ketergantungan pasien umumnya partial $(72,3 \%)$ dengan $57,3 \%$ hanya mendapatkan terapi cairan saja tanpa disertai pemberian obat melalui intravena. Balutan yang umum digunakan dalam penelitian ini adalah balutan transparan, yaitu 77,5\% (93 responden).

\section{Analisis Bivariat}

Analisis ini bertujuan untuk melihat hubungan variable bebas terhadap variable terikat dengan menggunakan uji wilcoxon pada batas kemaknaan 95\%. Pada analisis bivariat ini digunakan metode Life table sebagai estimasi fungsi ketahanan untuk tidak terkena flebitis. Dalam penelitian ini rentang pengamatan 72 jam dibagi menjadi 3 interval waktu, yaitu setiap 24 jam.

Berikut akan diuraikan hasil uji bivariat pada variable yang bermakna saja, yaitu jarak pemasangan dari persendian, cairan dan jenis balutan saja. 


\section{Hubungan Jarak Pemasangan Terapi Intravena dengan Probabilitas untuk Tidak Terkena Flebitis}

Pada responden yang dipasang terapi intravena $<3 \mathrm{~cm}$ dari persendian untuk tidak terkena flebitis didapatkan probabilitasnya 24 jam ketiga $85 \%$. Pada kelompok yang dipasang terapi intravena $3-7 \mathrm{~cm}$ dari persendian, probabilitas pada 24 jamketiga $78 \%$. Pada kelompok yang dipasang terapi intravena $7-14 \mathrm{~cm}$ dari persendian, probabilitas pada 24 jam ketiga $59 \%$. Sedangkan pada kelompok yang dipasang terapi intravena $>14 \mathrm{~cm}$ dari persendian, probabilitas pada 24 jam ketiga 58\%. Analisis lebih lanjut dengan uji Wilcoxon menunjukkan ada perbedaan yang signifikan antara jarak pemasangan dengan probabilitas untuk tidak mendapat flebitis. Untuk lebih jelasnya lihat Grafik 1.

\section{Grafik 1}

Probabilitas untuk tidak mendapat Flebitis menurut jarak pemasangan

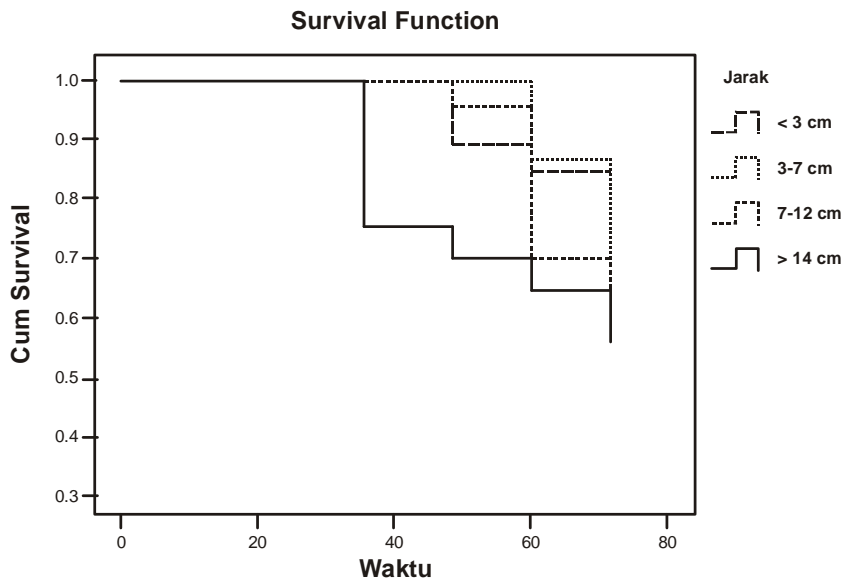

\section{Hubungan Jenis Cairan yang Diberikan dengan Probabilitas untuk Tidak Terkena Flebitis}

Pada responden yang hanya mendapatkan 1 jenis cairan dengan osmolalitas dan $\mathrm{pH}$ sama cairan tubuh (26 responden) diperoleh probabilitas untuk tidak mendapat flebitis pada 24 jam ketiga menjadi $72 \%$. Pada kelompok yang mendapatkan 2 cairan dengan osmolalitas dan $\mathrm{pH}$ normal didapatkan probabilitasnya pada 24 jam ketiga 54\%. Pada kelompok yang mendapatkan cairan dengan osmolalitas yang lebih tinggi atau $\mathrm{pH}$ lebih tinggi, probabilitas pada 24 jam ketiga 29\%.Analisis lebih lanjut dengan uji Wilcoxon menunjukkan ada perbedaan yang signifikan antara jenis cairan yang diterima dengan probabilitas untuk tidak mendapat flebitis. Untuk lebih jelasnya lihat Grafik 2.

Grafik2

Probabilitas untuk tidak mendapat Flebitis menurut jenis cairan

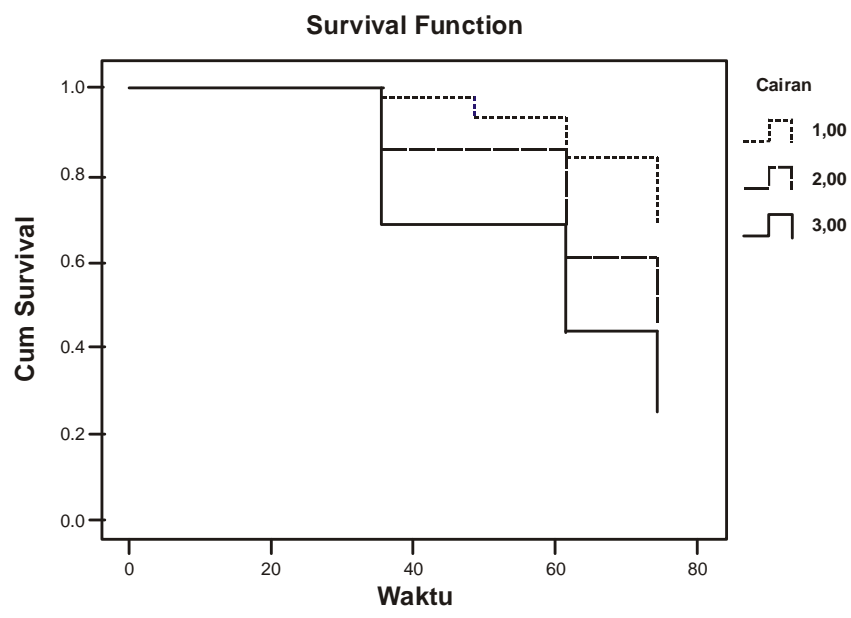

\section{Hubungan Jenis Balutan dengan Probabilitas untuk Tidak Terkena Flebitis}

Pada responden yang memakai balutan transparan (92 responden) diperoleh probabilitas untuk tidak mendapat flebitis pada 24 jam ketiga adalah $78 \%$. Pada kelompok yang memakai balutan Hypafix (8 responden) didapatkan probabilitasnya pada 24 jamketiga $75 \%$. Pada kelompok memakai balutan konvensional(19 responden), probabilitas pada 24 jam ketiga 35\%.Analisis lebih lanjut dengan uji Wilcoxon menunjukkan ada perbedaan yang signifikan antara jenis balutan yang diterima dengan probabilitas untuk tidak mendapat flebitis ( $p$ value 0,003 ). Untuk lebih jelasnya lihat Grafik 3

\section{Grafik 3}

Probabilitas untuk tidak mendapat Flebitis menurut jenis balutan

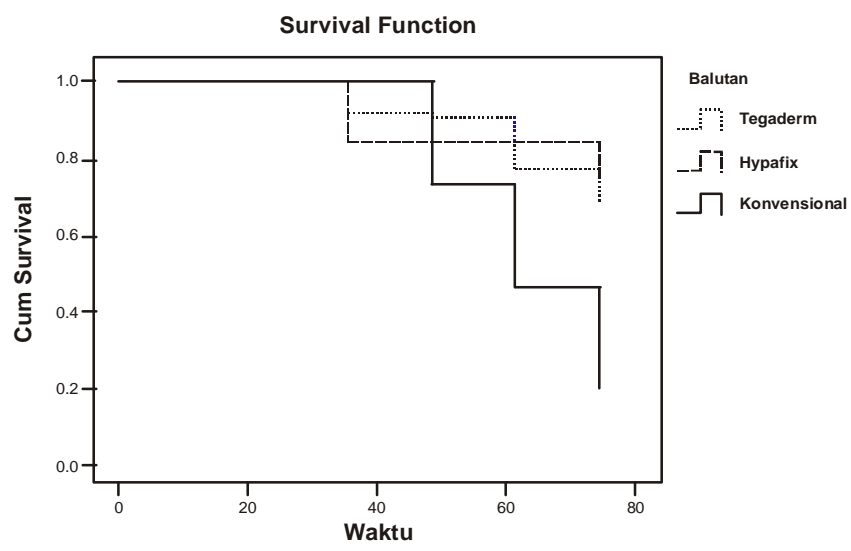




\section{Analisis Multivariat}

Analisis multivariat regresi cox dilakukan untuk menetapkan besarnya hubungan antarajarak pemasangan terapi intravena dengan risiko terkena flebitis setelah dikontrololeh variabel lain yang diduga sebagai confounding (Kleinbaum, 1996). Setelah melalui serangkaian tahapan dalam analisis multivariat disimpulkan bahwa bila dibandingkan dengan jarak pemasangan $<3 \mathrm{~cm}$, jarak pemasangan 3-7 cm mengurangi risiko terjadinya flebitis 0,54 kali. Sedangkan pada jarak $7-14 \mathrm{~cm}$ akan meningkatkan risiko 1,6 kali dan $>14 \mathrm{~cm}$ akan meningkatkan risiko 2,1 kali untuk terkena flebitis.

\section{PEMBAHASAN}

\section{Kejadian Flebitis}

Kejadian flebitis dalam penelitian ini cukup tinggi, yaitu $35,8 \%$. Perbedaan angka dalam penelitian ini dengan angka resmi yang dilaporkan dirumah sakit dapat disebabkan karena adanya perbedaan dalam menyatakan ada tidaknya flebitis. Dalam penelitian ini, flebitis tingkat I sudah dinyatakan sebagai flebitis namun di rumah sakit dinyatakan flebitis bila sudah mencapai tingkat III atau IV. Hal ini juga mungkin ada kaitannya dengan akreditasi rumah sakit. Angka dalam penelitian ini berbeda pula dengan laporan Sumarwati dan Pujasari, 2002 yang menyatakan angka kejadian flebitis umumnya yang diketahui di Indonesia berkisar 10\%

\section{Hubungan Jarak dengan Risiko Flebitis}

Variabel bebas utama dalam penelitian ini adalahjarak pemasangan terapi intravena dari persendian. Diketahuidari penelitian ini bahwa probabilitas untuk tidak terkena flebitis pada 24 jam ketiga menurut jarak adalah bila $<3 \mathrm{~cm}$ dari persendian adalah $85 \%$, jarak 3-7 cm dari persendian 78\%, jarak 7-14 cm dari persendian 59\% sedangkan sedangkan jarak $>14 \mathrm{~cm}$ dari persendian adalah 58\%. Disimpulkan dari hasil tersebut bahwa semakin jauh pemasangan maka probabilitas pada hari ke tiga untuk tidak terkena flebitis semakin menurun. Hasil yang serupa disimpulkan pula dari analisis multivariate yang dilakukan. Namun ada perbedaan penyimpulan hasil, yaitu pada jarak pemasangan $3-7 \mathrm{~cm}$ justru akan mengurangiprobabilitas untuk flebitis.

Sejalan dengan hasil tersebut maka dapat disimpulkan bahwa semakin jauh pemasangan maka risiko untuk terkena flebitis semakin meningkat. Flebitis yang terjadidalam penelitian initermasuk pada jenis flebitis mekanik. Angeles, 1997 menyatakan bahwa flebitis mekanik atau fisik dapat terjadi karena kanul yang terlalu besar untuk vena, iritasi vena selama pemasangan, atau adanya pergerakan kanul di dalam vena.

Dalam penelitian ini, jarak semakin jauh dapat meningkatkan risiko flebitis dimungkinkan karena keterkaitannya kurangnya fiksasi kanula sehingga kanula mudah bergerak dan mengiritasi. Selain itu diketahui pula apabila jarak pemasangan semakin jauh maka percabangan antara kanul dengan selang infuse akan semakin dekat dengan persendian yang lain. Hal inilah yang menyebabkan mengapa pada jarak 3-7 cm merupakan jarak yang paling aman untuk dipasangterapi infuse. Hasil penelitian ini sesuai dengan pendapat Angeles, 1997 yang menyatakan bahwa pergerakan kanul di dalam vena dinyatakan dapat menyebabkan flebitis ketika pasien bergerak dapat memicu pergerakan kanul sehingga melukai dinding pembuluh darah.

Faktor-faktor lain yang turut berkontribusi terjadinya flebitis dalam penelitian antara lain adalah jenis cairan yang diterima dan jenis balutan yang digunakan. Faktorfaktor tersebut dalam analisis lanjut ternyata bukanlah variabel pengganggu dalamhubungan jarak pemasangan dengan risiko flebitis.

Terapi cairan dalam penelitian ini mempunyai hubungan yang bermakna dengan risiko terkena flebitis. Semakin tinggi tipe cairan yang diterima pasien maka risiko untuk terkena flebitis semakin meningkat. Pendapat ini sejalan dengan pernyataan Angeless, 1997 dan lanbeck, et al, 2002 serta Lanbeck, et al, 2003 yaitu flebitis kimiawi disebabkan oleh iritasi obat atau cairan intravena yang terlalu asam atau basa ( $\mathrm{pH}<5$ atau $>9)$ serta larutan hipertonik (osmolalitas lebih dari 500mOsm/liter).

Tipe balutan yang digunakan dalam penelitian ini juga mempunyai hubungan yang bermakna dengan kejadian flebitis. Balutan transparan dan balutan hypafix tidak meningkatkan risiko untuk terkena flebitis namun balutan konvensional ternyata meningkatkan risiko sekitar 4 kali untuk terkena flebitis. Penggunaan balutan transparan dan hypafix ternyata dapat menurunkan risiko untuk terkena flebitis dibandingkan dengan balutan konvensional. Hal ini mungkin disebabkan karena penggunaan balutan konvensional harus mengalami penggantian balutan setiap 
hari sehingga dapat saja menyebabkan adanya kontak dengan kuman yang akhirnya flebitis supuratif terjadi. Penggantian balutan konvensional yang dilakukan setiap hari yang apabila tidak dilakukan dengan hati-hati juga dapat menyebabkan terjadinya flebitis mekanikal.

\section{KESIMPULAN}

Berdasarkan atas pembahasan dan uraian sebelumnya, maka dapat disimpulkan sebagai berikut:

1. Semakin jauh jarak pemasangan terapi intravena maka probabilitas pada hari ke tiga untuk tidak terkena flebitis semakin menurun.

2. Jarak pemasangan terapi infus yang paling menurunkan risiko terkena flebitis adalah $3-7 \mathrm{~cm}$.

3. Cairan dengan osmolalitas tinggi dapat meningkatkan risiko untuk terjadinya flebitis sebesar 4,5 kali dibandingkan dengan yang hanya menerima cairan dengan $\mathrm{pH}$ atau osmolalitas normal.

4. Pemakaian balutan konvensional akan meningkatkan risiko terjanya flebitis sebesar 4,3 kali dibandingkan dengan yang memakai balutan transparan.

5. Faktor-faktor lain yang turut diteliti dalam peneliti ini ternyata tidak berhubungan bermakna terhadap waktu terjadinya flebitis, seperti umur, jenis kelamin, jenis antibiotika, pengguyuran, atau tempat pemasangan.

\section{SARAN}

1. Perawat lebih memperhatikan agar jarak pemasangan terapi intravena tidak terlalu jauh atau pun terlalu dekat dengan sendi dan memperhatikan fiksasi pemasangan tersebut $(3-7 \mathrm{~cm})$.

2. Untuk mencegah terjadinya flebitis di rumah sakit, penlitian ini menyarankan agar perawat lebih menggunakan balutan transparan atau hypafix.

3. Penggantian set balutan infus yang terpasang pada klien lebih dari 72 jam.

4. Pada pasien yang menerima cairan dengan osmolalitas tinggi, sebaiknya dipilih vena dengan ukuran yang cukup besar agar kejadian terkena flebitis menurun

5. Perlunya dilakukan penelitian lanjutantentang pengaruh jarak pemasangan terapi intravena terhadap waktu terjadinya flebitis dengan jumlah pasien yang lebih besar dan desain yang lebih baik (YA).
* Penelitian ini didanai oleh Peneliti Madya FIK-UI tahun anggaran 2006/2007

** Dewi Gayatri, SKp, MKes dan Hanny Handiyani, SKp, MKep: Staf Akademik Kelompok Keilmuan Dasar Keperawatan dan Keperawatan Dasar Fakultas Ilmu Keperawatan Universitas Indonesia

\section{KEPUSTAKAAN}

Angeles, T. (1997). How to prevent phlebitis. Nursing 97. Vol.27:1

Craven, R. F. \& Hirnle, C.J. (2006). Fundamentals of nursing: Human health \& function. ( $3^{\text {rd }} \mathrm{ed}$.). Philladelphia: Lippincott Williams \& Wilkins.

Kleinbaum, D.G. (1996). Survival analysis: A self learning text. New York: Springer-Verlag

Kozier, B., Erb, G. Berman, A. J. \& Burke, K. (2000). Fundamentals of nursing . (sixth edition). St. Louis: Mosby

Lanbeck, P., Odenholt, I., \& Paulsen, O. (2002). Antibiotics differ in their tendency to cause infusion phlebitis: A prospective observational study. Scand Journal Infect. Dis. Vol. 34:7. Hal. 512-9

Lanbeck, P. Odenholt, \& I. Paulsen, O. (2003). Dicloxacillin: Ahigher risk than cloxacillin for infusion flebitis. Scand Journal Infect. Dis. Vol. 35:6-7. hal. 347-400

Murti, B. (1997). Prinsip dan metode riset epidemiologi. Yogyakarta: Gajah Mada University Press

Potter, P.A. \& Perry, A.G. (2001). Clinical nursing skills \& techniques. (third edition). St. louis: The C.V. Mosby Company

Pujasari, H \& Sumarwati, M. (2002). Angka kejadian flebitis dan tingkat keparahannya di ruang penyakit dalam di sebuah rumah sakit di Jakarta. Jurnal Keperawatan Indonesia. Vol 6(1), hal 1-5

Stevens \& Anderson. The practice of intravenous therapy improved through research utilization. Diambil dari www.google.com pada 2 Juli 2003. Workman, B. (1999). Peripheral intravenous therapy management. Nursing standard. Vol. 14: 4, hal 53-60 